\title{
Bone marrow stroma inhibits proliferation and apoptosis in leukemic cells through gap junction-mediated cell communication
}

\author{
FH Paraguassú-Braga ${ }^{1,2}$, R Borojevic ${ }^{2,3}$, LF Bouzas ${ }^{1}$, \\ MA Barcinski ${ }^{4,5}$ and A Bonomo ${ }^{*, 4,6}$ \\ ${ }^{1}$ Centro de Transplante de Medula Óssea, Instituto Nacional de Câncer, Rio de \\ Janeiro, Brazil \\ 2 Departamento de Histologia e Embriologia, Instituto de Ciências Biomédicas, \\ Universidade Federal do Rio de Janeiro, Rio de Janeiro, Brazil \\ 3 Programa Avançado de Biologia Celular Aplicada à Medicina, Hospital \\ Universitário Clementino Fraga Filho, Universidade Federal do Rio de Janeiro, \\ Rio de Janeiro, Brazil \\ ${ }^{4}$ Divisão de Medicina Experimental, Instituto Nacional de Câncer, Rio de \\ Janeiro, Brazil \\ ${ }^{5}$ Departamento de Parasitologia, Instituto de Ciências Biomédicas, \\ Universidade de São Paulo, São Paulo, Brazil \\ ${ }^{6}$ Departamento de Imunologia, Instituto de Microbiologia Professor Paulo de \\ Góes, Universidade Federal do Rio de Janeiro, Rio de Janeiro, Brazil \\ * Corresponding author: A Bonomo, Divisão de Medicina Experimental, \\ Coordenação de Pesquisa, Instituto Nacional de Câncer, Praça da Cruz \\ Vermelha, $23-6^{\circ}$ andar, Rio de Janeiro, RJ 20230-130, Brazil. Tel: + 5521 \\ 2506 6107; Fax: + 55212224 4148; E-mail: abonomo@ inca.gov.br
}

Received 06.2.03; revised 11.4.03; accepted 29.4.03

Edited by $\mathrm{V}$ De Laurenzi

\begin{abstract}
Normal and leukemic blood cell progenitors depend upon the bone marrow (BM) stroma with which they communicate through soluble and membrane-anchored mediators, adhesive interactions and gap junctions (GJ). Regarding hematopoiesis, it is believed that it can be influenced by connexin expression, but the exact role of GJ in cell death and proliferation is not clear. Using flow cytometry, we monitored the division rate of leukemic cell lines, communicating and not communicating with stromal cell line through GJ. We found that GJ-coupled cells (i) did not proliferate; (ii) were kept in G0; and (iii) were protected from drug-induced apoptosis when compared to either total or uncoupled cell population. We conclude that GJ coupling between stroma and leukemic lymphoblasts prevents proliferation, keeping cells in a quiescent state, thus increasing their resistance to antimitotic drugs. Since GJ are particularly abundant in the sub-endosteal environment, which harbors blood stem cells, we also asked which cells within the normal human BM communicate with the stroma. Using a primary BM stroma cell culture, our results show that $80 \%$ of $\mathrm{CD} 34+$ progenitors communicate through GJ. We propose that blood cell progenitors might be retained in the low-cycling state by GJ-mediated communication with the hematopoietic stroma. Cell Death and Differentiation (2003) 10, 1101-1108. doi:10.1038/ sj.cdd. 4401279
\end{abstract}

Keywords: gap junctions; connexin; leukemia; stem cell; proliferation; apoptosis

\begin{abstract}
Abbreviations: 7AAD, 7-aminoactinomycin D; $A O$, acridine orange; $\mathrm{BM}$, bone marrow; $\mathrm{CBX}$, carbenoxolone; $\mathrm{Cx}$, connexin; GJ, gap junction; GJIC, gap junction intercellular communication; Da, Daltons; MTX, methotrexate
\end{abstract}

\section{Introduction}

In adult mammals, bone marrow (BM) is the major site of hematopoiesis. The BM is composed of hematopoietic and stromal cells, blood vessels, nerves and extracellular matrix proteins. ${ }^{1,2}$ The cellular components interact through intercellular communications, cytokines and hormones, ${ }^{3}$ which together determine the rate of blood cell production and renewal. The result of all these interactions is the adequacy of hematopoiesis for the systemic needs, specifically regulating the number of cells in each compartment.

The interactions between hematopoietic and stromal cells are also important for the maintenance of the undifferentiated pluripotent and long-lived stem cell. ${ }^{3-5}$ Besides communication via surface ligands and their corresponding receptors, cells can communicate through gap junctions (GJs): specialized membrane structures that bridge the cytoplasms of the interacting cells. They are formed by connexins (Cx's), which are proteins inserted into the plasma membrane as a hemichannel or connexon. ${ }^{6}$ A complete gap junction pore is formed by the association of two hemichannels from two communicating cells. ${ }^{7}$ This pore is permissive for the exchange of water, inorganic ions, small metabolites and secondary messengers, allowing functional integration of continuous cell systems. Early ultrastructural and subsequent cytochemical studies of the BM hematopoietic environment had described GJs in the stroma and blood vessels. ${ }^{8-11}$ Transfer of Lucifer Yellow (a GJ probe) among stromal cells and between stromal and blood cells had shown the existence of functional GJ-mediated cell interactions. ${ }^{12,13}$ This was further confirmed by the demonstration of electric cell coupling between purified immature progenitors and a stromal cell line. ${ }^{14}$

Association of increased $\mathrm{Cx}$ expression and increased blood cell production has raised the hypothesis that Cx's could participate in the control of hematopoiesis. ${ }^{11,15,16}$ This hypothesis was subsequently confirmed in studies on mice with targeted disruption of the gene encoding $\mathrm{Cx} 43 .{ }^{17}$ These animals presented a deficient capacity to regenerate blood cell production after cytoablative treatments. Moreover, using radiation chimeras, the authors showed that impaired $\mathrm{T}$ - and B-lymphocyte maturation was due to a defect in the stromal cells of both the thymus and BM. This confirms Rosendaal hypothesis ${ }^{11,15,18}$ that $\mathrm{Cx} 43$ expression in the stroma is critical during early growth and regeneration of the hematopoietic system, but not for maintenance of the steady-state blood cell production. 
Similar to normal hematopoiesis, proliferation of leukemic cells is also largely dependent upon the BM environment. ${ }^{19,20}$ In leukemia, a small number of autorenewable clonogenic cells, leukemic stem cells, ${ }^{21,22}$ depend upon the stroma to survive. ${ }^{23-25}$ Their quantification reflects disease malignancy and predicts treatment outcome. ${ }^{20}$ Several studies had clearly shown that leukemic cell adhesion to stroma, which involves adhesion molecules as integrins and CD44, or juxtacrine interactions, as those mediated by c-Kit, supports leukemic lymphoblasts survival and protects them from apoptosis. ${ }^{4,24}$

In the present study, we have addressed the question of whether GJ-mediated intercellular communications (GJIC) between the stroma and leukemic cells can control cell growth and death. We have established an in vitro model using the S17 murine bone marrow stroma cell line and some leukemic lines. Similar to other murine cell lines, S17 cells sustain longterm ex vivo growth of human blood cell progenitors. ${ }^{26-29}$ By monitoring the calcein dye transfer from the stroma to leukemic cells we could describe, using flow cytometry, the effect of GJIC on leukemic cell growth and death. Moreover, using human BM, we address which hematopoietic cells communicate through GJ when plated over primary stromal cultures.

\section{Results}

\section{Morphology of stromal-leukemic cell cocultures, and identification of GJ-mediated cell communication}

Morphological analysis of stromal-leukemic cell line cocultures showed similarity to primary long-term BM cultures. ${ }^{30}$ Leukemic cells infiltrated the pre-established stroma, forming typical cobblestone areas (Figure 1a), which are representative of primitive hematopoietic progenitor-cell niches in vitro. ${ }^{31}$ Ultrastructural analysis showed close cell membrane contacts, suggesting juxtacrine interactions (Figure $1 \mathrm{~b}$ and $\mathrm{c}$ ). In order to check if GJs could take place between the stroma and the leukemic cell line studied, we looked for the presence of message for various Cx's in both cell lines. Indeed, as shown in Figure 1d and e, both S17 and CCRF-CEM lymphoblasts express mRNA for several connexins. Regarding protein expression, several studies had shown the importance of Cx43 for the establishment of GJ between BM cells. ${ }^{12-15,17,32}$ Using immunofluorescence, we also detected Cx43 in a typical punctuate distribution on both cell membranes (data not shown). Functional GJ-mediated communications in S17 cell layers were also confirmed by intercellular transference of Lucifer Yellow, a $457 \mathrm{Da}$ dye permeable only through GJs (data not shown).

We monitored the presence of GJ-mediated cell interactions between leukemic and stromal cell lines using calcein loading-transfer assay. Calcein is a 623 Da fluorescent dye, permeable only through GJ, which can be read on the flow cytometer, enabling functional studies of coupled and uncoupled cell population, with minimum manipulation. Calcein was loaded into the S17 stroma, which was cocultured with leukemic blasts for 3 days, and analyzed by flow cytometry. Owing to the great difference of light dispersion, S17 stroma and leukemic cells can be easily
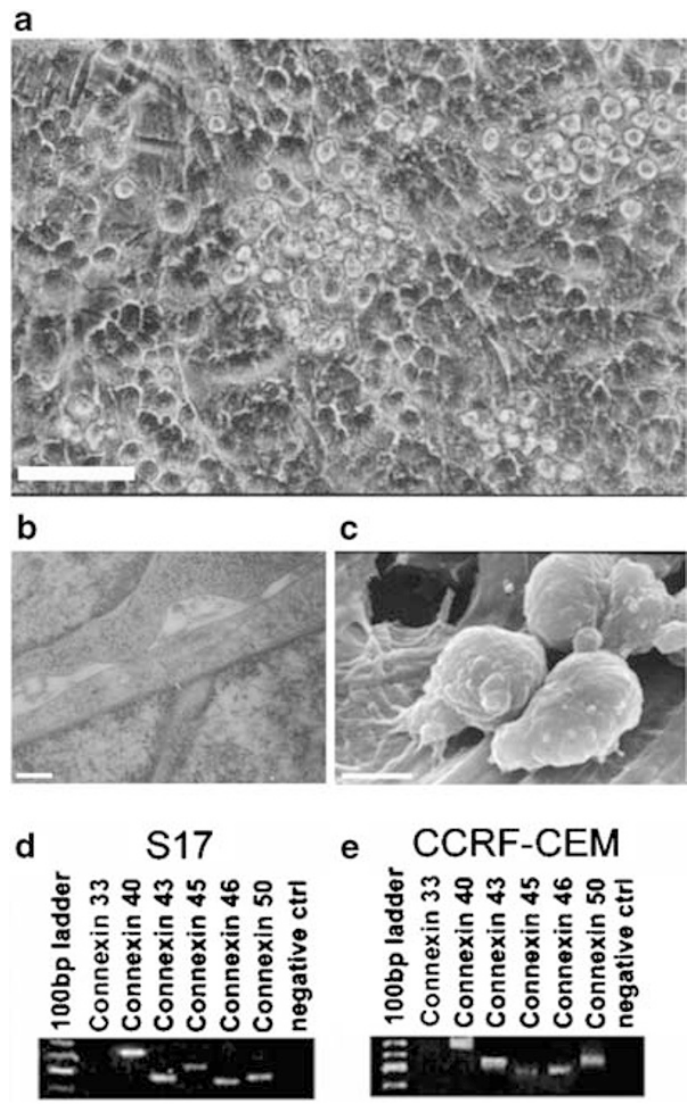

Figure 1 Morphological aspects of interaction between CCRF-CEM leukemia cell line and S17 stroma cell line. (a) S17 and CCRF-CEM cell aspect at phase contrast microscopy. Infiltrating lymphoblasts can be identified by lack of light transmission forming typical cobblestone areas. Noninfiltrating blasts are seen growing over the stroma as bright cells (bar=21 $\mu \mathrm{m})$. (b) S17/CCRF-CEM coculture at transmission electron microscopy $(\mathrm{bar}=0.25 \mu \mathrm{m})$. (c) S17/CCRFCEM coculture aspect at scanning electron microscopy. Leukemic cells show extensive membrane processes over the stroma cell $(\mathrm{bar}=5 \mu \mathrm{m})$. (d) mRNA Cx expression in murine $\mathrm{S} 17$ cell line and (e) in human CCRF-CEM lymphoblast cell line. Amplicons size variability between ( $D$ and $E$ ) are due to species-specific differences in $\mathrm{Cx}$ genes

distinguished by forward and side scatter, as shown in Figure 2. Transfer of dye between stroma and leukemic cells was readily detectable after $72 \mathrm{~h}$ of coculture, when $20 \%$ of leukemic blasts were labeled with calcein (Figure 2b). Contamination of labeled stromal cells in the leukemic gate was discarded since, at day 0 , no fluorescence was detected in the assigned gate (Figure 2a), while cells in the stroma gate showed extremely high levels of fluorescence labeling.

Thus, the above results indicate the presence of functional GJ between leukemic and stromal cell lines.

\section{GJIC increases the number of cells in the G0 phase of the cell cycle and inhibits cell proliferation}

Cell cycle kinetics was monitored in order to study the influence of stroma-dependent cell interactions on leukemic cell proliferation.

Acridine orange (AO), which stains DNA and RNA in different colors, was used in order to distinguish cells in G0, 
a
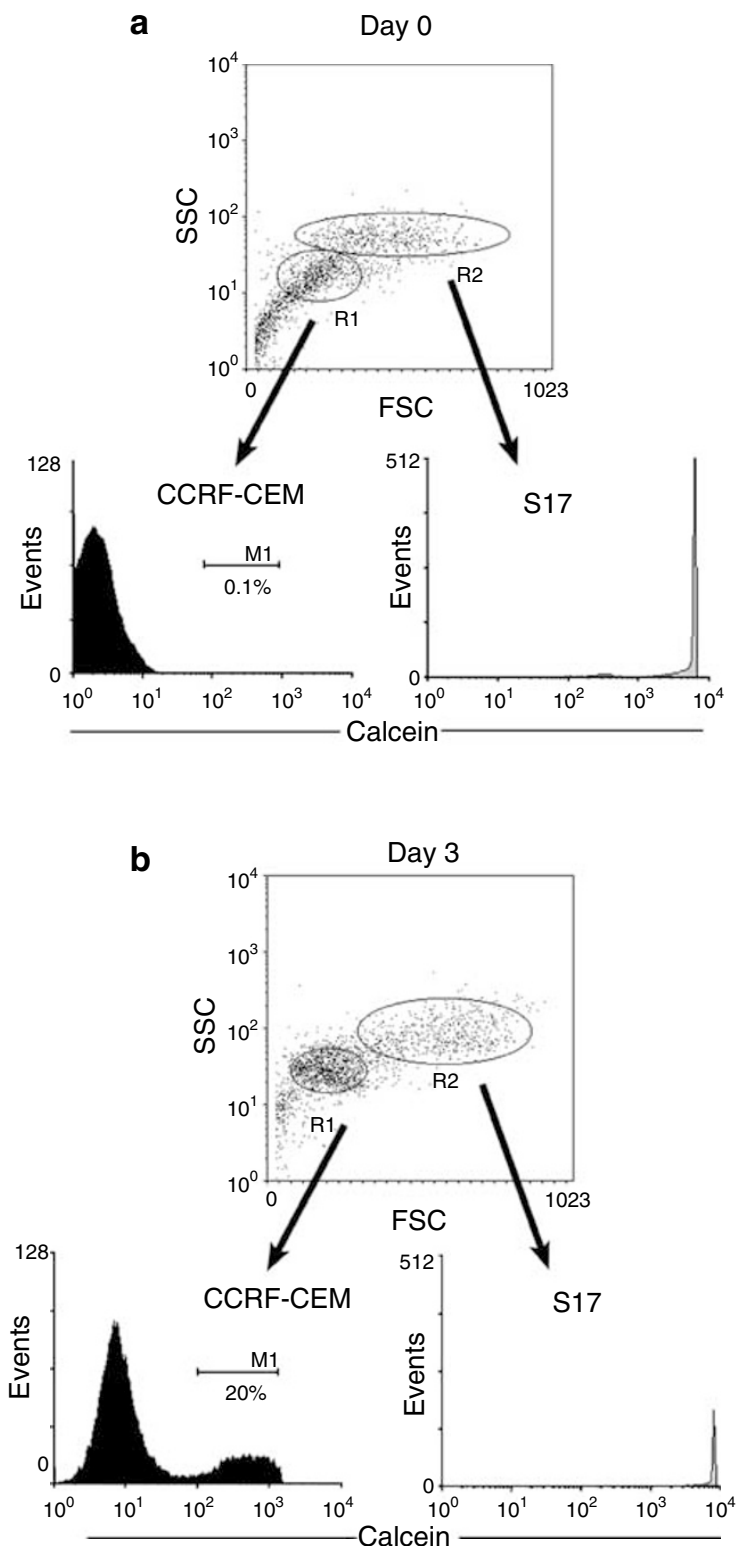

Figure 2 Flow cytometry strategy for calcein loading-transfer assay to measure GJIC between stroma cells and leukemic cells after 3-day coculture. S17 cells loaded with calcein were cocultured for 0- (a) and 3- (b) day period with CCRFCEM cells. Leukemic cells were analyzed for calcein fluorescence under the leukemic gate (a and $\mathbf{b}$, lower left), while S17 used the stromal gate (a and $\mathbf{b}$, lower right). Note the low background level of fluorescence observed in the CCRF-CEM gate at day 0 (a, lower left). At day 3, GJ-mediated communication was quantified within the leukemic cell population (b, lower left). This experiment is representative of four independent assays

G1 and S/G2/M phases of the cell cycle. Figure 3 shows that in stroma-free cultures (white bars), almost all the CCRF-CEM cells are committed to the cell cycle, with $49 \%$ of the cells in G1 and $47 \%$ in S/G2/M. However, when cultured with S17 cells, commitment with the cell cycle diminishes, and the number of cells in S/G2/M drops to $28 \%$ (light gray bars). Even more striking is the increase from $3 \%$, in stroma-free cultures, to $20 \%$ in the number of cells in G0 in the cocultures (light gray bars). With respect to cell proliferation, these results indicate

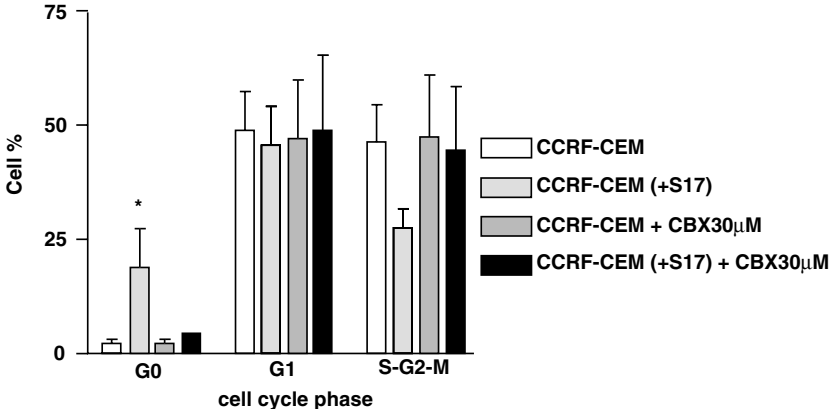

Figure 3 Cell cycle analysis of CCRF-CEM cells grown either in the presence or absence of $S 17$ stroma. AO was used to distinguish G0, G1 and S/G2/M as explained in Material and Methods. Leukemic cells were cultured alone (white and dark gray bars) and in the presence of stroma cells (light gray and black bars) without (white and light gray bars) and with CBX (dark gray and black bars). Percentages of cells in G0, G1 and S/G2/M phases of the cell cycle are indicated. Mean of four experiments. ${ }^{*}$ means $P<0.05 t$-paired test

that the stroma has an inhibitory effect, which cannot be attributed to an arrest in $\mathrm{G} 1$, but rather to an effect that retains the cells in a quiescent state (G0).

To investigate the role of GJs over the cell cycle, we used carbenoxolone (CBX), a drug that inhibits $\mathrm{GJIC}^{33,34}$ in the cocultures of CCRF-CEM with S17 and deserved the different phases of the cell cycle using $\mathrm{AO}$ as above (Figure 3 - black bars). Carbenoxolone abrogated the increase in the number of cells in the G0 phase of the cycle, showing the modulation of leukemic cell cycle by GJ.

The use of calcein loading-transfer assay led us to monitor directly the effect of GJIC on leukemic cell proliferation. Using calcein and PKH 26 red dye, we monitored the proliferation of leukemic cells, cultured alone and in the presence of $S 17$ cell line. Leukemic cells that established a functional gap junction with stroma (calcein positive) were distinguished from those that did not (calcein negative) as shown in Figure 2. When compared to control cultures, CCRF-CEM/S17 cocultures carried out in trans-wells as well as calcein-negative cells, showed little cell proliferation changes (Figure 4a). Strikingly, whenever GJIC was established, calcein-positive cells had an intense growth inhibition (Figure 4a). To verify if the inhibition observed above was exclusive to CCRF-CEM, we additionally tested two acute myeloid leukemias, HL60 and KG1. Both cell lines can differentiate in vitro into different lineages, indicating some pluripotentiality. ${ }^{35-37}$ Confirming the results observed with communicating CCRF-CEM, both HL60- and KG1 calcein-positive cells have their division index close to zero (Figure $4 \mathrm{~b}$ and c). It is important to emphasize that calcein per se does not interfere with leukemic cell proliferation (Figure 4a, inset). Thus, the above results indicate that stroma-leukemia GJs inhibit cell proliferation, with the induction of a quiescent nonproliferative state in the leukemic cells.

\section{GJ inhibits drug-induced cell death}

Cell population kinetics depends upon the rate of cell growth and death. We found a correlation between cell proliferation inhibition mediated by GJs and the presence of cells in the G0 phase of the cell cycle described above. However, the role of 
a
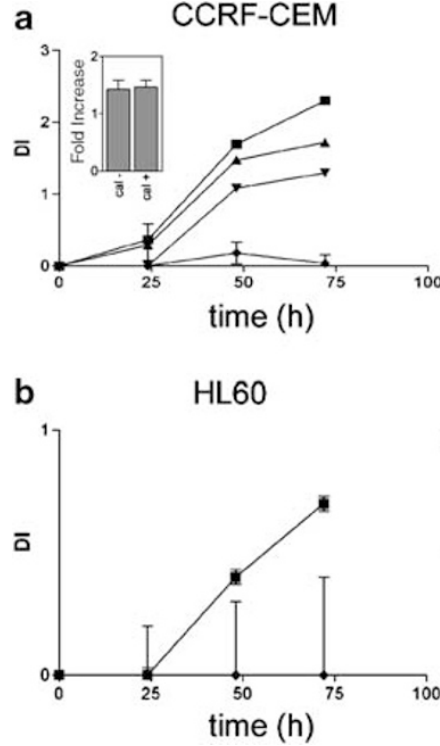

C

KG1

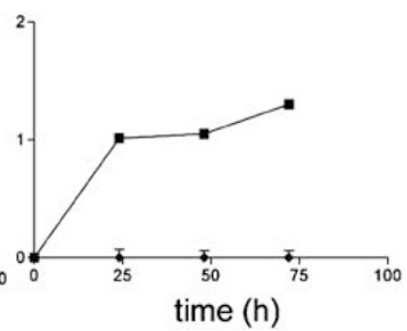

Figure 4 GJ-mediated intercellular communication with $\$ 17$ inhibits proliferation of leukemia cells. Division index of CCRF-CEM cells (a) growing without (control) and with stroma, either coupled (cal + ) or not (cal-) and without stroma contact (noncontact) was calculated based on PKH26 red (FL2) decay as described in Material and Methods. Note that calcein does not alter CCRF-CEM proliferation (inset). Proliferation pattern of HL60 (b) and KG1 (c) cells cultured in the absence of stroma and with stroma. The results for stroma-free cells and $\mathrm{cal}+$ are shown. Bars indicate $95 \%$ confidence interval. Representative of three experiments

GJIC between stroma and leukemic cells in cell death is still undetermined. We have addressed this issue by associating calcein loading-transfer assay with 7-amino actinomycin (7AAD) staining, monitoring viability and apoptotic cell death. CCRF-CEM cells have some degree of spontaneous apoptosis when grown in the absence of S17. When in coculture with $\mathrm{S} 17$ cells, viability and spontaneous apoptosis of calceinnegative leukemic cells was not different from those of control cultures (Figure 5a - gray and white bars, respectively). However, coupled cells showed a nonsignificant, but a consistently small increase in the percentages of viable cells. Conversely, there was a small decrease in the percentages of apoptotic cells (Figure $5 \mathrm{a}$ - black bars).

Stromal cells are believed to be responsible not only for the survival of leukemic cells in pathological conditions but also during chemotherapeutic treatments. ${ }^{38}$ In order to test whether GJs could protect leukemic cells from drug-induced apoptosis, cell cultures were treated for $24 \mathrm{~h}$ with methotrexate (MTX). This drug inhibits dihydrofolate reductase, an enzyme critical for DNA synthesis and cell proliferation. Under these conditions, leukemic cell viability fell below $50 \%$, while apoptosis increased over $50 \%$ (Figure $5 b$ - white bars). When leukemic cells were maintained over a calcein-loaded S17 stroma, calcein-positive cells viability increased up to $80 \%$, while apoptosis dropped below $25 \%$, representing a protection above $50 \%$ (Figure $5 \mathrm{~b}$ - black bars) when compared with MTX-treated noncoupled cells (Figure 5b - gray bars).

Taken together, these results indicate that GJIC modulate both leukemic cell proliferation and death. a

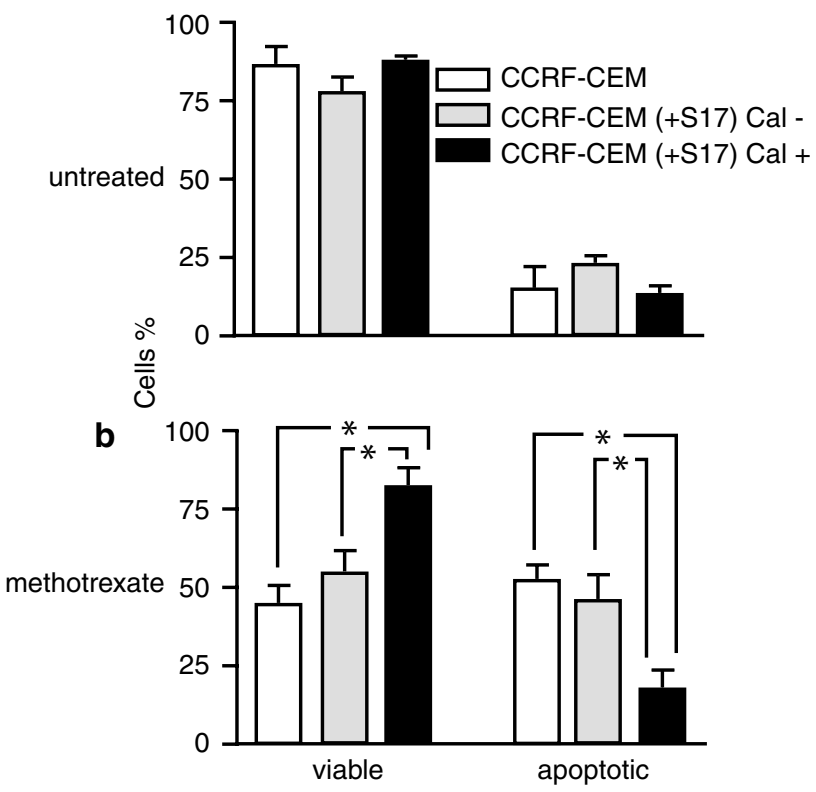

Figure 5 Influence of GJ-mediated intercellular communication of stroma and leukemic cells over life and death of leukemic blast. Cells were cultivated as for standard calcein loading-transfer assay $(72 \mathrm{~h}$ ) and analyzed with 7AAD for apoptosis quantification. Untreated (a) and MTX ( $1 \mu \mathrm{M}$ for the last $24 \mathrm{~h})$ treated cultures (b). Relative numbers of viable and apoptotic cells are indicated. Stromafree cultures (white bars), nonstroma-coupled leukemia (gray bars) and GJ stroma-coupled leukemic cells (black bars). "means $P<0.05$ t-paired test

\section{CD34 + progenitor cells communicate through GJ with human stromal cells in primary cultures}

A stem cell's major characteristic is its ability to self-renew and perpetuate its progeny. This ability is frequently related to a low proliferation rate that keeps cells quiescent. Adding to this, our results point to the role of GJ in the cell cycle, inhibiting proliferation and keeping cells in a quiescent state. On the other hand, GJ is known to be particularly abundant in the subendosteal environment that harbors blood stem cells. ${ }^{10,11,39}$ Altogether, we propose that if $\mathrm{GJ}$ is important to keep the stem cells quiescent within BM hematopoietic cells, CD34 ${ }^{+}$cells should be able to establish GJIC with stromal cells.

To answer this question, a human primary stromal culture was established, loaded with calcein and cocultured with whole human BM cells. After a 3-day culture, cells were stained with anti-CD34PE and anti-CD45 PercP mAb and analyzed in the flow cytometer for the presence of calcein. Figure 6 shows that $80 \%$ of CD34 + cells do communicate through GJ with the stroma, while only $15 \%$ of CD34- are calcein positive, suggesting that GJ might play a role in the maintenance of normal stem cells.

\section{Discussion}

GJs can integrate electrically or metabolically large tissue sectors and delimited cell clusters. In BM, Cx43 is expressed on bone-lining endosteal and reticular stromal cells that are in direct contact with hematopoietic progenitors and on endothelial cells. ${ }^{10,11}$ This $\mathrm{BM}$ region was recognized to be a 


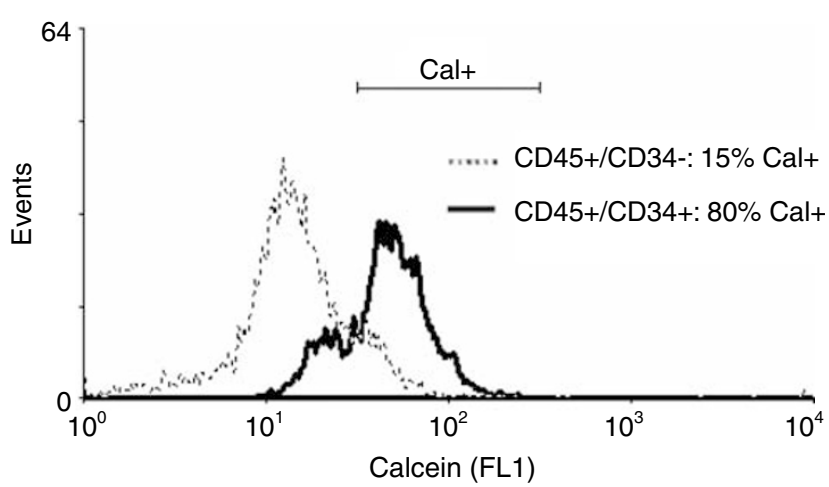

Figure 6 Functional GJ analysis of ex vivo primary bone marrow cells. Primary hematopoietic bone marrow cells were cocultured with primary stroma cells. Primary stroma cells were loaded with calcein and after 3-day culture, all cells were detached and stained for hematopoietic stem/progenitor cells (CD45 and CD34). Histograms show calcein staining for CD45 + /CD34 + and CD45+/ CD34 - gated populations. Most hematopoietic early progenitor/stem cells $(80 \%$ of CD $45+/ C D 34+)$ are cal + , indicating functional coupling via GJs with primary stroma

niche for homing of stem and early hematopoietic progenitors. ${ }^{40}$ Also, Cx43 GJ are upregulated during development and after cytoablative treatment. ${ }^{15}$ In Cx43 knockout mice, the number of hematopoietic stem cells (Sca- $1^{+} /$Lin $^{-}$) was clearly reduced, ${ }^{17}$ and male germ stem cells were significantly reduced. ${ }^{41}$ Corroborating for the involvement of GJ in stem cell regulation, purified human immature CD34 ${ }^{+}$progenitors had been shown to communicate with a stromal cell line through Cx43 GJs. ${ }^{14}$ In fact, in bulk BM hematopoietic population, $80 \%$ of the more immature CD34 ${ }^{+} \mathrm{CD} 45^{+}$cells do connect to the stroma through GJ, while the more mature pool does not (Figure 6), suggesting a possible role for this interaction in the maintenance of the stem cell pool.

The fate of a stem cell, malignant or not, is to maintain itself and perpetuate its progeny. ${ }^{42}$ This property has been suggested to be associated with quiescence, while engaging in cycling has been related to differentiation. ${ }^{43}$ The mechanisms maintaining the 'stemness' are unknown, but certainly involve cell cycle arrest. Moreover, GJ has long been implicated in malignant cell development and differentiation. ${ }^{44,45}$

With our results, we further suggest that $G J$ is at least one of the mediators of cell cycle regulation. We show that leukemic cells communicating with the stroma do not proliferate (Figure 4). Cell cycle studies demonstrate that these leukemic cells are arrested in G0, since treatment with $\mathrm{CBX}$, an uncoupling agent, inhibits the increase in the number of cells in G0 (Figure 3) when in coculture with stroma.

Through an indirect assay, GJs have been proposed to make hematopoietic stem cells escape stromal inhibition ${ }^{46,47}$ and to engage in proliferation, commitment and production of blood cells. ${ }^{18}$ In contrast, using a direct assay, we have shown that GJs are actually involved in the maintenance of quiescence. We also suggest that such regulation can be achieved through signaling for asymmetric cell division. GJs are permeable to second messengers, such as CAMP, which can polarize asymmetric cell divisions. ${ }^{48}$ Thus, the reduced amount of stem cells in the murine Cx43-KO phenotype ${ }^{17,41}$ could be interpreted as the loss of asymmetry resulting in proliferation and differentiation with loss of 'stemness'. Besides elimination of cell growth (Figure 4), our results show nearly $50 \%$ inhibition of drug-induced apoptosis in leukemic cells that communicate with the stroma (Figure 5). This inhibition of drug-induced apoptosis is probably due to an arrest in the G0 phase of the cell cycle, which was dependent upon the GJIC (Figure 3). Resistance to drug-induced apoptosis may explain the quiescent carcinoma micrometastasis and residual disease observed in the BM, which are associated with poor prognosis. ${ }^{20}$

Cell proliferation and programmed cell death are opposed in tissue homeostasis, but each one depends in part upon rather similar cell mechanisms: many molecules involved in signal transduction leading to cell proliferation are shared with common death signal pathways. ${ }^{49,50}$ This gives rise to the idea that cell cycle and apoptosis are not opposing events and can thus be regulated by the same mediators.

Altogether, the data presented herein can add to the understanding of the mechanisms that contribute to the maintenance of normal and malignant stem cells. We are currently investigating the role of $\mathrm{GJ}$ in micrometastasis and normal stem cell maintenance.

\section{Materials and Methods}

\section{Cell cultures}

Cell lines were obtained from the Rio de Janeiro Cell Bank (BCRJ, Federal University of Rio de Janeiro, Brazil). Murine S17 BM stroma cells were used according to authorization by Dr K Dorshkind. ${ }^{27}$ Routinely, cells were maintained in the RPMl-1640 medium (Sigma, St Louis, MO, USA) supplemented with $10 \%$ fetal bovine serum (FBS - HyClone, Logan, UT,

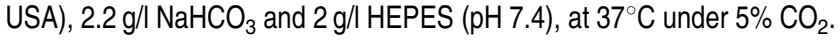
All the experiments were carried out using $\mathrm{S} 17$ cells below the 29th passage of the original stock. All leukemic cells were maintained in the same medium, with cell density kept at $10^{5}-10^{6}$ cells $/ \mathrm{ml}$. Cocultures consisted of leukemic cells $\left(10^{5} / \mathrm{ml}\right)$ plated over semiconfluent layers of S17 cells. When indicated, the leukemic CCRF-CEM cells were cultured in the upper compartment of trans-well culture plates $(0.45 \mu \mathrm{m}-$ Nunc, Roskilde, Denmark), with $\mathrm{S} 17$ cells in the lower compartment.

Normal primary BM samples were obtained from healthy BM transplantation donors under informed consent. Primary BM stroma were generated by cultivating Ficoll-Hypaque-treated BM (Histopaque ${ }^{\mathrm{TM}}$, Sigma) in McCoy 5 A medium supplemented with $10 \%$ v/v FBS (HyClone) and $2 \mathrm{mM} \mathrm{L-Glu} \mathrm{(Sigma),} \mathrm{namely} \mathrm{M10.} \mathrm{Cultures} \mathrm{were} \mathrm{plated} \mathrm{in} 75 \mathrm{~cm}^{2}$ cell culture vessels for over 2 weeks before the first passage. Primary BM stroma cultures were used between second and fourth passages. Coculture of normal BM stem/progenitor cells with primary BM stroma was performed using mononuclear cells from BM, after a $24 \mathrm{~h}$ period of adhesion in M10 media. After this, cells were harvested, counted and plated $\left(10^{6} / \mathrm{ml}\right)$ over confluent PBMS.

Cell viability was evaluated before every plating using trypan blue exclusion assay. Viability was always superior to $95 \%$ at the beginning of each experiment.

\section{RT-PCR}

S17 or CCRF-CEM cells were collected and treated with 1-ml Trizol ${ }^{\mathrm{TM}}$ (Gibco-BRL/Life Technologies Inc., Grand Island, NY, USA), followed by 


\begin{tabular}{lll}
\hline $\mathbf{c x}$ & Sense & Antisense \\
\hline Cx37 & GAACATCAGATGGCCAAGAT & GGATCATAAACAGTGGAACT \\
Cx40 & GCACACTGTGCGCATGCAGG & CTGCTGGCCTTACTAAGGCG \\
Cx43 & CTCCAGTGGTACATCTATGG & CTTAGCATTGGACAGGTAGAGA \\
Cx45 & TGGAGCATGGTGAGGCAGAC & CCTCTGCCTTGCGCATCGTT \\
Cx46 & GGAACCAATGCGTACAGGGA & GGGCTGGTCTCCACCAT \\
\hline
\end{tabular}

PCR cycles were: $96^{\circ} \mathrm{C} 3$ min (denaturation), 33 cycles with 30 s at $96^{\circ} \mathrm{C}, 30$ s at $55^{\circ} \mathrm{C}$ (annealing) and 60 s at $72^{\circ} \mathrm{C}$ (polymerization). Samples were submitted to $72^{\circ} \mathrm{C}$ for $10 \mathrm{~min}$ for final polymerization extension. Thermal cycle was performed in an automated programmed thermal cycler (Perkin-Elmer)

total RNA extraction according to the manufacturer's protocols. Firststrand cDNA synthesis was carried out using $1 \mu \mathrm{g}$ RNA, Poli-dT primers and Superscript II (Gibco-BRL) according to the manufacturer's instructions. Primers sequence and PCR reaction parameters were performed as described in Table 1.

Amplicons were analyzed on standard agarose electrophoresis gel, using ethidium bromide and visualized by UV-transilluminator apparatus, and registered with Eagle Eye (Stratagene, La Jolla, USA) digital gel acquisition system.

\section{Flow cytometry}

\section{Stem/progenitor cell staining}

Normal bone marrow cultures and cocultures were suspended with EDTA (Sigma) solution ( $0.05 \%$ in phosphate-buffered saline, PBS) for $10 \mathrm{~min}$ at $37^{\circ} \mathrm{C}$. Cells were washed with PBS containing $2 \%$ of normal human $A B$ serum, incubated with anti-CD45-PERCP (Pharmingen) and anti-CD34PE (Pharmingen), for 20 min, washed and fixed.

The flow cytometry studies were carried out using a FACSCAN ${ }^{\circledR}$ cytometer with a CellQuest ${ }^{\mathbb{B}}$ (Beckton Dickinson, San José, CA, USA) support software, and analyzed with WINMDI ${ }^{\mathbb{R}}$ PC application.

\section{Electron microscopy}

S17 cells were plated in 24-well tissue culture plates on top of polystyrene coverslips (Nunc, Roskilde, Denmark), and grown to confluence. $1 \times 10^{3}$ CCRF-CEM cells $/ \mathrm{ml}$ were plated over the $\mathrm{S} 17$ monolayer and cultured for $72 \mathrm{~h}$. Coverslips with stroma and leukemic cells were fixed with glutharaldehyde and routinely processed for transmission and scanning electron microscopy (TEM and SEM) as previously described. ${ }^{51}$

\section{Calcein transfer assay for GJ-mediated intercellular communication}

GJ-mediated intercellular communications between the stroma and leukemic cells were monitored by flow cytometry, following the protocol described by Czyz et al. ${ }^{52}$ with slight modifications. Briefly, stroma cells were grown to semiconfluence $\left(5 \times 10^{4}\right.$ cells $\left./ \mathrm{cm}^{2}\right)$ in six- 12-or 24-well plates. They were washed with $0.9 \% \mathrm{NaCl}$ solution followed by an RPMI1640 culture medium. Stroma monolayers were loaded with $1 \mu \mathrm{M}$ calcein AM (Molecular Probes, Eugene, OR, USA) for $2 \mathrm{~h}$, and extensively washed with a serum-free followed by serum-supplemented medium. After removal of the extracellular calcein, leukemic cells were added in $1: 1$ ratio in the latter medium. Control cultures of leukemic and stroma cells were prepared simultaneously. After $72 \mathrm{~h}$, cells were trypsinized and washed with PBS supplemented with 5\% FBS, fixed in 4\% paraformaldehyde in PBS and analyzed by flow cytometry.

When indicated, CBX (Sigma, St Louis, MO, USA) was used in the coculture system to inhibit GJ-mediated cell communication. Control assays indicated that $30 \mu \mathrm{M} \mathrm{CBX}$ was devoid of cytotoxic effect for stroma and leukemic cells.

\section{Cell cycle analysis}

In order to dissociate $\mathrm{G} 0$ and $\mathrm{G} 1$ cell cycle phases of leukemic cells maintained with or without the S17 stroma, DNA and RNA content were measured using $A O{ }^{53}$ Briefly, leukemic and stroma cells were harvested as described, and cell suspensions were adjusted to $2 \times 10^{6}$ cells $/ \mathrm{ml}$ with PBS containing $5 \%$ FBS. Subsequently, $200 \mu \mathrm{l}$ was transferred to flow cytometer tubes and supplemented with $500 \mu \mathrm{l}$ denaturing solution $(0.3 \%$ saponin, $0.08 \mathrm{~N} \mathrm{HCl}$ and $0.15 \mathrm{~N} \mathrm{NaCl}$ ) and incubated for $15 \mathrm{~min}$ on ice, followed by $1.5 \mathrm{ml}$ staining solution (citrate-phosphate buffer, $\mathrm{pH} 6.0$, $0.15 \mathrm{~N} \mathrm{NaCl}, 1 \mathrm{mM}$ EDTA- $\mathrm{Na}_{4}$ and $10 \mu \mathrm{g} / \mathrm{ml} \mathrm{AO}$ ). The resulting suspension was analyzed by flow cytometry within $15 \mathrm{~min}$. For acquisition, double discrimination mode was used with FL1. Data were plotted for analysis as FL1A (for DNA) $\times$ FL3H in linear scale (for RNA). Cells in GO are discriminated as they show the same amount of DNA (FL1A) as cells in G1, with less RNA (lower FL3H)

\section{PKH 26 cell labeling and cell proliferation}

Leukemic cell proliferation was monitored with or without the underlying stroma (control) using the PHK26-GL red dye (Sigma, St Louis, MO, USA) as previously described. ${ }^{54}$

Cocultures were carried out as described above. At the indicated time points, the cells were harvested and the data acquired on the flow cytometer. For analyses, CCRF-CEM cells were gated based on SSC/ FSC parameters and FL1 staining (cal + or cal-) and DI was calculated according to FL2 fluorescence decay as proposed by Ashley et al. ${ }^{54}$ Accordingly

$$
\begin{aligned}
& 2^{\mathrm{DI}}=F_{0} / F_{\mathrm{T}} \\
& \text { As though } \\
& \log 2^{\mathrm{DI}}=\left(\log F_{0} / F_{\mathrm{T}}\right) \\
& \mathrm{DI} \log 2=\left(\log F_{\mathrm{O}} / F_{\mathrm{T}}\right) \\
& \mathrm{DI}=\left(\log F_{\mathrm{o}} / F_{\mathrm{T}}\right) / \log 2
\end{aligned}
$$

where $\mathrm{DI}$ is the division index, $F_{0}$ is the geometric mean of fluorescence at time 0 , and $F_{\mathrm{T}}$ is the geometric mean of fluorescence at time $T$.

The $95 \%$ confidence interval $(\mathrm{Cl} 95 \%)$ of $\mathrm{DI}$ was calculated by

$$
\mathrm{DI} \pm 2 \sqrt{p \mathrm{EPF}_{0}^{2}+p \mathrm{EPF}_{\mathrm{T}}^{2}}
$$




\section{Apoptosis}

The (7AAD Molecular Probes) staining was used as a simple and accurate method for detecting apoptosis. 7AAD was dissolved in DMSO (Sigma) at $10 \mathrm{mg} / \mathrm{ml}$ stock solution. A working solution was prepared by diluting it to $200 \mu \mathrm{g} / \mathrm{ml}$ and kept at $-20^{\circ} \mathrm{C}$ protected from light. Staining was performed as described by Philpott et al. ${ }^{55}$ with minor modifications. Briefly, leukemic cells cultured in the presence or absence of calceinloaded stroma were harvested, and washed in PBS containing 5\% FBS. A volume of $20 \mu \mathrm{l}$ of $7 \mathrm{AAD}(200 \mu \mathrm{g} / \mathrm{ml})$ was added to the final pellet, and incubated for $30 \mathrm{~min}$, protected from light. Cells were subsequently washed with PBS containing 5\% FBS, fixed with $4 \%$ paraformaldehyde in PBS and analyzed in a flow cytometer within $30 \mathrm{~min}$. Viable, early or late apoptotic cells were identified according to the red fluorescence intensity (FL3) after gating, either calcein-positive or -negative leukemic cells.

For the study of MTX-induced apoptosis, leukemic cells cultured alone or with $\mathrm{S} 17$ stroma were grown for $48 \mathrm{~h}$. MTX was subsequently added to the culture medium at a final concentration of $1 \mu \mathrm{M}$, and apoptosis was monitored after $24 \mathrm{~h}$.

\section{Acknowledgements}

We thank Jose Dias Correa Jr and Dr Marcos Farina for their kind support in electron microscopy procedures. Thanks are due to Dr Regina Goldenberg and Dr Antonio Carlos Campos de Carvalho for their expertise, intellectual and technical support, especially at the beginning of this work. We also thank the staff of the Umbilical Cord Blood Bank/Center for Bone Marrow Transplantation and colleagues of the Experimental Medicine Division, both of the National Cancer Institute/Brazil for their day by day support and acquaintance. Finally, we thank Aniela Improta França, our English reviewer, who did an excellent work in editing the article.

This work was financially supported by PRONEX, CNPq, FAF-INCa, and FAPERJ. A publication of the Millennium Institute of Tissue Bioengineering.

\section{References}

1. Yamazaki K and Allen TD (1990) Ultrastructural morphometric study of efferent nerve terminals on murine bone marrow stromal cells, and the recognition of a novel anatomical unit: the 'neuro-reticular complex'. Am. J. Anat. 187: 261-276

2. Charbord $P$, Tavian M, Humeau $L$ and Peault $B$ (1996) Early ontogeny of the human marrow from long bones: an immunohistochemical study of hematopoiesis and its microenvironment. Blood 87: 4109-4119

3. Torok-Storb B (1988) Cellular interactions. Blood 72: 373-385

4. Verfaillie CM (1998) Adhesion receptors as regulators of the hematopoietic process. Blood 92: 2609-2612

5. Ploemacher RE, Mayen $A E$, De Koning $A E$, Krenacs $T$ and Rosendaal $M$ (2000) Hematopoiesis: gap junction intercellular communication is likely to be involved in regulation of stroma-dependent proliferation of hemopoietic stem cells. Hematology 5: 133-147

6. Kumar NM and Gilula NB (1996) The gap junction communication channel. Cell 84: $381-388$

7. Yeager M, Unger VM and Falk MM (1998) Synthesis, assembly and structure of gap junction intercellular channels. Curr. Opin. Struct. Biol. 8: 517-524

8. Watanabe $Y$ (1985) Fine structure of bone marrow stroma. Nippon Ketsuek Gakkai Zasshi 48: 1688-1700

9. Campbell FR (1980) Gap junctions between cells of bone marrow: an ultrastructural study using tannic acid. Anat. Rec. 196: 101-107

10. Krenacs $T$ and Rosendaal M (1998) Connexin43 gap junctions in normal, regenerating, and cultured mouse bone marrow and in human leukemias: their possible involvement in blood formation. Am. J. Pathol. 152: 993-1004

11. Rosendaal M (1995) Gap junctions in blood forming tissues. Microsc. Res. Technol. 31: 396-407
12. Rosendaal M, Gregan A and Green CR (1991) Direct cell-cell communication in the blood-forming system. Tissue Cell 23: 457-470

13. Dorshkind K, Green L, Godwin A and Fletcher WH (1993) Connexin-43-type gap junctions mediate communication between bone marrow stromal cells. Blood 82: 38-45

14. Durig J, Rosenthal C, Halfmeyer K, Wiemann M, Novotny J, Bingmann D, Duhrsen U and Schirrmacher K (2000) Intercellular communication between bone marrow stromal cells and CD34+ haematopoietic progenitor cells is mediated by connexin 43-type gap junctions. Br. J. Haematol. 111: 416-425

15. Rosendaal M, Green CR, Rahman A and Morgan D (1994) Up-regulation of the connexin43+ gap junction network in haemopoietic tissue before the growth of stem cells. J. Cell. Sci. 107: 29-37

16. Krenacs $T$ and Rosendaal M (1995) Immunohistological detection of gap junctions in human lymphoid tissue: connexin43 in follicular dendritic and lymphoendothelial cells. J. Histochem. Cytochem. 43: 1125-1137

17. Montecino-Rodriguez $\mathrm{E}$, Leathers $\mathrm{H}$ and Dorshkind $\mathrm{K}$ (2000) Expression of connexin 43 (Cx43) is critical for normal hematopoiesis. Blood 96: 917-924

18. Rosendaal M, Mayen A, de Koning A, Dunina-Barkovskaya $T$, Krenacs $T$ and Ploemacher R (1997) Does transmembrane communication through gap junctions enable stem cells to overcome stromal inhibition? Leukemia 11: 1281-1289

19. Bradstock KF and Gottlieb DJ (1995) Interaction of acute leukemia cells with the bone marrow microenvironment: implications for control of minimal residual disease. Leukemia Lymphoma 18: 1-16

20. Kumagai M, Manabe A, Pui CH, Behm FG, Raimondi SC, Hancock ML, Mahmoud H, Crist WM and Campana D (1996) Stroma-supported culture in childhood B-lineage acute lymphoblastic leukemia cells predicts treatment outcome. J. Clin. Invest. 97: 755-760

21. Bradstock K, Bianchi A, Makrynikola V, Filshie R and Gottlieb D (1996) Longterm survival and proliferation of precursor-B acute lymphoblastic leukemia cells on human bone marrow stroma. Leukemia 10: 813-820

22. Weber MC and Tykocinski ML (1994) Bone marrow stromal cell blockade of human leukemic cell differentiation. Blood 83: 2221-2229

23. Konopleva M, Konoplev S, Hu W, Zaritskey AY, Afanasiev BV and Andreeff M (2002) Stromal cells prevent apoptosis of AML cells by up-regulation of antiapoptotic proteins. Leukemia 16: 1713-1724

24. Lagneaux L, Delforge A, De Bruyn C, Bernier M and Bron D (1999) Adhesion to bone marrow stroma inhibits apoptosis of chronic lymphocytic leukemia cells. Leukemia Lymphoma 35: 445-453

25. Bradstock K, Bianchi A, Makrynikola V, Filshie R and Gottlieb D (1996) Longterm survival and proliferation of precursor-B acute lymphoblastic leukemia cells on human bone marrow stroma. Leukemia 10: 813-820

26. Gluck U, Zipori D, Wetzler M, Berrebi A, Shaklai M, Drezen O, Zaizov R, Luria D, Marcelle C and Stark B (1989) Long-term proliferation of human leukemia cells induced by mouse stroma. Exp. Hematol. 17: 398-404

27. Collins LS and Dorshkind K (1987) A stromal cell line from myeloid long-term bone marrow cultures can support myelopoiesis and B lymphopoiesis. J. Immunol. (Baltimore, MD.: 1950) 138: 1082-1087

28. Dorshkind K (2002) Multilineage development from adult bone marrow cells. Nat. Immunol. 3: 311-313

29. Nolta JA, Thiemann FT, Arakawa_Hoyt J, Dao MA, Barsky LW, Moore KA, Lemischka IR and Crooks GM (2002) The AFT024 stromal cell line supports long-term ex vivo maintenance of engrafting multipotent human hematopoietic progenitors. Leukemia 16: 352-361

30. Dexter TM and Lajtha LG (1974) Proliferation of haemopoietic stem cells in vitro. Br. J. Haematol. 28: 525-530

31. Ploemacher RE, van der Voerman JS and Brons NH (1989) An in vitro limitingdilution assay of long-term repopulating hematopoietic stem cells in the mouse. Blood 74: 2755-2763

32. Cancelas JA, Koevoet WL, de_Koning AE, Mayen AE, Rombouts EJ and Ploemacher RE (2000) Connexin-43 gap junctions are involved in multiconnexin-expressing stromal support of hemopoietic progenitors and stem cells. Blood 96: 498-505

33. Chaytor AT, Marsh WL, Hutcheson IR and Griffith TM (2000) Comparison of glycyrrhetinic acid isoforms and carbenoxolone as inhibitors of EDHF-type relaxations mediated via gap junctions. Endothelium 7: 265-278

34. Ozog MA, Siushansian R and Naus CC (2002) Blocked gap junctional coupling increases glutamate-induced neurotoxicity in neuron-astrocyte co-cultures. J. Neuropathol. Exp. Neurol. 61: 132-141 
35. Gallagher R, Collins S, Trujillo J, McCredie K, Ahearn M, Tsai S, Metzgar R, Aulakh G, Ting R, Ruscetti F and Gallo R (1979) Characterization of the continuous, differentiating myeloid cell line (HL-60) from a patient with acute promyelocytic leukemia. Blood 54: 713-733

36. Collins SJ, Ruscetti FW, Gallagher RE and Gallo RC (1978) Terminal differentiation of human promyelocytic leukemia cells induced by dimethyl sulfoxide and other polar compounds. Proc. Natl. Acad. Sci. USA 75: 2458-2462

37. Koeffler HP (1981) Human myelogenous leukemia: enhanced clonal proliferation in the presence of phorbol diesters. Blood 57: 256-260

38. Panayiotidis P, Jones D, Ganeshaguru K, Foroni L and Hoffbrand AV (1996) Human bone marrow stromal cells prevent apoptosis and support the survival of chronic lymphocytic leukaemia cells in vitro. Br. J. Haematol. 92: 97-103

39. Nilsson SK, Johnston HM and Coverdale JA (2001) Spatial localization of transplanted hemopoietic stem cells: inferences for the localization of stem cell niches. Blood 97: 2293-2299

40. Lord BI, Testa NG and Hendry JH (1975) The relative spatial distributions of CFUs and CFUc in the normal mouse femur. Blood 46: 65-72

41. Roscoe WA, Barr KJ, Mhawi AA, Pomerantz DK and Kidder GM (2001) Failure of spermatogenesis in mice lacking connexin43. Biol. Reprod. 65: 829-838

42. Reya T, Morrison SJ, Clarke MF and Weissman IL (2001) Stem cells, cancer, and cancer stem cells. Nature 414: 105-111

43. Glimm H, Oh I-H and Eaves CJ (2000) Human hematopoietic stem cells stimulated to proliferate in vitro lose engraftment potential during their S/G2/M transit and do not reenter G0. Blood 96: 4185-4193

44. Esinduy CB, Chang CC, Trosko JE and Ruch RJ (1995) In vitro growth inhibition of neoplastically transformed cells by non-transformed cells: requirement for gap junctional intercellular communication. Carcinogenesis 16: $915-921$

45. Yamasaki $\mathrm{H}$ (1991) Aberrant expression and function of gap junctions during carcinogenesis. Environ. Health Perspect. 93: 191-197
46. Hurley RW, McCarthy JB and Verfaillie CM (1995) Direct adhesion to bone marrow stroma via fibronectin receptors inhibits hematopoietic progenitor proliferation. J. Clin. Invest. 96: 511-519

47. Verfaillie CM and Catanzaro P (1996) Direct contact with stroma inhibits proliferation of human long-term culture initiating cells. Leukemia 10: 498-504

48. Brummendorf TH, Dragowska W and Lansdorp PM (1999) Asymmetric cell divisions in hematopoietic stem cells. Ann. NY Acad. Sci. 872: 265-272

49. Hsieh JK, Kletsas D, Clunn G, Hughes AD, Schachter M and Demoliou-Mason C (2000) p53, p21(WAF1/CIP1), and MDM2 involvement in the proliferation and apoptosis in an in vitro model of conditionally immortalized human vascular smooth muscle cells. Arterioscler. Thromb. Vasc. Biol. (Online) 20: 973-981

50. Wang XW (1999) Role of p53 and apoptosis in carcinogenesis. Anticancer Res. 19: $4759-4771$

51. Borojevic R, Monteiro AN, Vinhas SA, Domont GB, Mourao PA, Emonard H, Grimaldi $G$ and Grimaud JA (1985) Establishment of a continuous cell line from fibrotic schistosomal granulomas in mice livers. In vitro Cell. Dev. Biol.: J. Tissue Culture Assoc. 21: 382-390

52. Czyz J, Irmer U, Schulz G, Mindermann A and Hulser DF (2000) Gap-junctional coupling measured by flow cytometry. Exp. Cell Res. 255: 40-46

53. Darzynkiewicz Z, Traganos F, Sharpless T and Melamed MR (1976) Lymphocyte stimulation: a rapid multiparameter analysis. Proc. Natl. Acad. Sci. USA 73: 2881-2884

54. Ashley DM, Bol SJ, Waugh C and Kannourakis G (1993) A novel approach to the measurement of different in vitro leukaemic cell growth parameters: the use of PKH GL fluorescent probes. Leukemia Res. 17: 873-882

55. Philpott NJ, Turner AJ, Scopes J, Westby M, Marsh JC, Gordon-Smith EC, Dalgleish AG and Gibson FM (1996) The use of 7-amino actinomycin D in identifying apoptosis: simplicity of use and broad spectrum of application compared with other techniques. Blood 87: 2244-2251 